OPEN ACCESS

Edited by:

Caroline Isaksson,

Lund University, Sweden

Reviewed by:

Pierre J. Deviche,

Arizona State University, United States

Jose A. Masero,

University of Extremadura, Spain

*Correspondence:

Clotilde Biard

clotilde.biard@upmc.fr

Frédéric Angelier

Frederic.angelier@cebc.cnrs.fr

Specialty section:

This article was submitted to Behavioral and Evolutionary Ecology,

a section of the journal

Frontiers in Ecology and Evolution

Received: 31 March 2017 Accepted: 03 July 2017

Published: 18 July 2017

Citation:

Biard C, Brischoux F, Meillère A Michaud B, Nivière M, Ruault $S$, Vaugoyeau $M$ and Angelier F (2017)

Growing in Cities: An Urban Penalty for Wild Birds? A Study of Phenotypic Differences between Urban and Rural

Great Tit Chicks (Parus major).

Front. Ecol. Evol. 5:79.

doi: 10.3389/fevo.2017.00079

\section{Growing in Cities: An Urban Penalty for Wild Birds? A Study of Phenotypic Differences between Urban and Rural Great Tit Chicks (Parus major)}

\author{
Clotilde Biard $^{1 *}$, François Brischoux ${ }^{2}$, Alizée Meillère ${ }^{2}$, Bruno Michaud ${ }^{2}$, Manon Nivière $^{1}$, \\ Stéphanie Ruault ${ }^{2}$, Marie Vaugoyeau ${ }^{1}$ and Frédéric Angelier ${ }^{2 *}$ \\ ${ }^{1}$ Institut d'Écologie et des Sciences de l'Environnement de Paris, Sorbonne universités, UPMC Université Paris 06, UPEC, \\ Paris 7, Centre National de la Recherche Scientifique, Institut National de la Recherche Agronomique, IRD, Paris, France, \\ ${ }^{2}$ Centre d'Etudes Biologiques de Chizé, Centre National de la Recherche Scientifique-ULR, UMR 7372, Villiers en Bois, \\ France
}

Urban sprawl is associated with deep and intense modifications of the natural habitats of wild vertebrates. Although, many species are unable to cope with such an environment, a few species can be found in cities and can help us assessing the impact of urbanization on wildlife. Urban-related environmental modifications are multiple and some of them seem beneficial while others seem rather detrimental to wild vertebrates. Moreover, the impact of these modifications on wild vertebrates is likely to vary depending on the phase of the annual life-cycle. Therefore, it is challenging to get a comprehensive picture of the impact of urbanization on wild vertebrates. Overall, urbanization is usually associated with reduced breeding performances in wild birds, but the impact of urbanization on the phenotype and quality of developing offspring has been less studied. In this study, we specifically investigated the impact of urbanization on several proxies of individual quality in great tits (Parus major). We concomitantly measured body size (tarsus length and body mass), plumage coloration, and telomere length in 14-days old chicks issued from 4 populations (two pairs of urban/rural populations located in two different geographical areas of France). First, rural chicks were significantly taller and heavier than urban birds although this impact of urbanization on body size/body mass appears only true for the most urbanized site. Interestingly, body size was also affected by the geographical area of capture, suggesting that regional environmental conditions may attenuate or exacerbate the influence of urbanization on nestling growth. Second, the carotenoid-based yellow plumage of rural nestlings was more colorful than that of urban birds, independently of the area of capture. This suggests that urban birds probably have a low-carotenoid diet relative to rural birds. Finally, telomere length did not differ between rural and urban chicks. These results suggest that urbanization probably imposes large developmental constraints in wild vertebrates and that this impact may primarily be related to constraining nutritional conditions.

Keywords: urbanization, carotenoid-based signal, developmental conditions, telomeres, body size, plumage color 


\section{INTRODUCTION}

Urban sprawl is a worldwide phenomenon that deeply affects environmental conditions, and consequently, avian biodiversity (Grimm et al., 2008; Shanahan et al., 2014). Thus, cities are characterized by multiple abiotic and biotic modifications of the natural environment such as fragmentation (Crooks et al., 2004), human disturbance (Sauvajot et al., 1998; FernándezJuricic, 2002), and increased pollutions: noise (Slabbekoorn and Peet, 2003; Meillère et al., 2015b), light (Dominoni et al., 2013; Spoelstra and Visser, 2014), electromagnetic (Engels et al., 2014), and chemical pollution (Roux and Marra, 2007; Isaksson, 2010; Bichet et al., 2013). Urbanization is also associated with altered predation risk (Fischer et al., 2012; Møller and IbáñezÁlamo, 2012), inter and intra-specific competition (Duckworth, 2014), disease prevalence (Bichet et al., 2013; Giraudeau et al., 2014), food type and abundance (Robb et al., 2008; Harrison et al., 2010; Galbraith et al., 2015). All these modifications raise new important selective constraints for wild vertebrates, and as a consequence, biodiversity is overall impoverished in cities (Clergeau et al., 2006; McKinney, 2008). While some species seem unable to cope with this modified environment (urban avoiders) others can still be found in this specific environment (urban-tolerant species, Chace and Walsh, 2006). Comparative studies have allowed ecologists to determine the specific characteristics that may be compatible with an urban way of life in wild vertebrates (Møller, 2008, 2009; Evans et al., 2011; Sol et al., 2013; Jokimäki et al., 2016). In addition, an individual-based approach is also necessary to fully understand the ecological processes that may constrain the ability of wild populations to cope with urbanization (Gil and Brumm, 2014). Several studies have for instance demonstrated that living in an urban environment is associated with phenotypical changes in vertebrates (e.g., body size: Bókony et al., 2012; Meillère et al., 2017, secondary sexual signals: Fuller et al., 2007; Giraudeau et al., 2015, stress physiology: Bonier, 2012, immunity: Audet et al., 2015). Moreover, a large number of studies have also shown that urbanization affects reproductive performances, such as phenology or the number of young produced (Both et al., 2004; Chamberlain et al., 2009; Ausprey and Rodewald, 2011; Stracey and Robinson, 2012; Deviche and Davies, 2014; Møller et al., 2015).

Surprisingly, the influence of urbanization on the phenotype and quality of developing offspring has been much less studied (Heiss et al., 2009; Seress et al., 2012; Salmón et al., 2016). Early developmental conditions are however crucial to study because they are known to have important long-term consequences on individual phenotypes and adult performances (survival and reproduction, Lindström, 1999; Metcalfe and Monaghan, 2001; Monaghan, 2008). In terms of nutritional conditions, urbanization is very likely to be constraining for most bird species. Several studies have shown that the urban environment is associated with modifications of the arthropod community (Helden et al., 2012), and thus, with a lack of protein-rich diet (McIntyre et al., 2001; Shochat et al., 2004), vitamins, carotenoids (Isaksson and Andersson, 2007; Møller et al., 2010; Giraudeau and McGraw, 2014; Giraudeau et al., 2015), and calcium (Heiss et al., 2009). Similarly, urban-related disturbance is likely to affect the quality of parental care (e.g., incubation commitment or brood provisioning, Ibáñez-Álamo and Soler, 2010; Seress et al., 2011; Meillère et al., 2015a), and therefore the nutritional conditions of offspring. In addition, other urban-related environmental conditions could also constrain the development of offspring through direct or parental-mediated effects (e.g., chemical pollution, light pollution, intra- and interspecific competition, predation risk, Shanahan et al., 2014).

In this study, we aimed to better understand the consequences of living in an urban environment for developing wild vertebrates. To do so, we propose to study concomitantly several complementary proxies of developmental conditions (growth, carotenoid-based coloration, and telomere length). First, growth is classically used to monitor nutritional developmental conditions in wild vertebrates and poor nutritional conditions are associated with delayed growth, an overall poor health status and a lower probability to fledge and to recruit into the population (Gebhardt-Henrich and Richner, 1998; Naef-Daenzer and Keller, 1999; Naef-Daenzer et al., 2001). Second, carotenoids are also relevant to study because plasma carotenoid levels are known to be positively associated with immunity (Saino et al., 2003b; Biard et al., 2005; Cucco et al., 2006), and growth (Tschirren et al., 2003; Biard et al., 2005, 2006; Berthouly et al., 2008). In addition to these physiological functions, carotenoids are also allocated into carotenoid-based signals (e.g., plumage) in developing animals (Fitze et al., 2003; Isaksson et al., 2006). Such signaling is crucial because it is used by parents to assess the viability/quality of the chicks and therefore to determine their parental investment (Saino et al., 2003a; Pike et al., 2007; Thorogood et al., 2011). Therefore, carotenoids mediate a tradeoff between protective physiological functions (e.g., immunity, growth, and antioxidants) and signaling in developing animals. Because carotenoids cannot be synthetized by vertebrates and are only acquired through the diet (Isaksson, 2009), carotenoidbased plumage appear relevant to better assess the environmental constraints associated with an urban way of life in developing vertebrates (Giraudeau et al., 2015). Third, offspring survival is also classically used because it is a direct measure of reproductive success. However, it is often very challenging to follow the young after fledging in wild populations, and therefore, longterm survival is difficult to assess. In that respect, telomere length appears as a promising molecular marker to assess the survival probability of offspring after fledging (Monaghan, 2010, 2014). Telomeres are long repetitive sequences of noncoding DNA that are located at the end of chromosomes. They protect chromosomes from degradation and they also play a crucial role during the replication process (Blackburn, 2000). Telomeres usually shorten as individual age, and importantly, environmental stressors and the occurrence of oxidative stress have been shown to accelerate this shortening (von Zglinicki, 2002). Moreover, telomere length has also been linked with survival (Barrett et al., 2013; Fairlie et al., 2016) and it can be used as a reliable proxy of an individual's longevity (Heidinger et al., 2012).

Several studies have examined the influence of urbanization on these variables. For instance, urbanization often delays and 
impairs growth in bird species (Chamberlain et al., 2009; Heiss et al., 2009; Seress et al., 2012; Bailly et al., 2016). Similarly, urbanization is often associated with lower offspring productivity in wild vertebrates (Chamberlain et al., 2009; Bailly et al., 2016). However, these results appear somewhat inconsistent and sometimes differ between species or populations (reviewed in Chamberlain et al., 2009). Overall, carotenoid-based plumage color is paler in birds living in cities than in those living in rural areas (Eeva et al., 1998; Hõrak et al., 2000, 2001; Isaksson et al., 2005; Giraudeau and McGraw, 2014; Giraudeau et al., 2015). The influence of urbanization on telomere length has only been investigated a few times in wild animals (Salmón et al., 2016; Stauffer et al., 2017), and further studies are necessary to confirm that urbanization could lead to shortened telomeres in developing wild animals.

In this study, we investigated the influence of urbanization on growth, offspring survival, offspring carotenoid-based coloration and offspring telomere length in a wild bird species, the great tit (Parus major). To our knowledge, no study has concomitantly investigated the influence of urbanization on all these variables and their functional links remain unclear in an urbanization context. Moreover, most studies have only compared a rural and an urban population, preventing to assess the influence of the degree of urbanization on these variables. Here, we examined this question by comparing four populations of great tits. In addition to two rural sites, we studied two urban sites with contrasted degrees of urbanization: a very large city (Paris), and a medium-sized city (Niort) in France, Western Europe. Great tit is a relevant species for such a study because it is considered as an urban adapter species (Shochat et al., 2006; Kark et al., 2007), and it can be found in rural sites, but also all along the urbanization gradient (Croci et al., 2008). Moreover, as cavity-nesters, the development of the chicks is very easy to follow (Lambrechts et al., 2010). According to previous studies, we predict that urbanization will be detrimental to developing chicks. First, we predict that growth will be impaired in cities relative to rural areas. Second, we predict, that urban nestlings will be less colorful than rural ones because of a lack of carotenoid-rich diet in cities. Third, we predict that urban nestlings will have shorter telomeres due to increased developmental stress than rural ones. Importantly, we predict that these effects should be reinforced as the degree of urbanization increases. If telomere length and carotenoid-based coloration are two proxies of health status and individual quality, we finally predict that carotenoid-based coloration and telomere length will be positively correlated with growth.

\section{MATERIALS AND METHODS}

\section{Study Sites and Data Collection}

Data were collected in 2014 in two pairs of rural and urban populations of greattits breeding in France: (i) in the Paris area, and more specifically in city parks of Paris $\left(48^{\circ} 17^{\prime} \mathrm{N}, 2^{\circ} 38^{\prime}\right.$ E) and in the forest surrounding the Foljuif field station, $80 \mathrm{~km}$ down south of Paris (CEREEP; $48^{\circ} 16^{\prime} \mathrm{N}, 2^{\circ} 41^{\prime} \mathrm{E}$ ), and (ii) in the Niort area, and more specifically in the city of Niort $\left(46^{\circ} 18^{\prime} \mathrm{N}\right.$, $0^{\circ} 28^{\prime} \mathrm{W}$ ) and nearby forest of Chizé-CEBC, $30 \mathrm{~km}$ down south of Niort $\left(46^{\circ} 09^{\prime} \mathrm{N}, 0^{\circ} 24^{\prime} \mathrm{W}\right)$. The rural study sites of Foljuif and Chizé respectively contained 120 and 100 nestboxes (Schwegler wood-concrete nest boxes $2 \mathrm{M}$, Valliance, Saint Pierre La Palud, France, floor area: $113 \mathrm{~cm}^{2}$ ) evenly distributed throughout homogenous deciduous woodlands composed mainly of oak (Quercus spp.), hornbeam (Carpinus betulus) and beech (Fagus sylvatica), and used by both blue and great tits (entrance hole diameter: $32 \mathrm{~mm}$ ). The urban study sites of Paris and Niort contained respectively 60 and 64 nestboxes (Paris: 40 Schwegler nest boxes $2 \mathrm{M}$, and 20 handmade nestboxes in wooden panel, floor area: $105 \mathrm{~cm}^{2}$, entrance hole diameter: $32 \mathrm{~mm}$; Niort: 64 Schwegler nest boxes $2 \mathrm{M}$ ) installed in several urban parks or cemetery, separated from one another by $1-7 \mathrm{~km}$ as the crow flies. Paris is the biggest city in France ( $\sim 2$ million inhabitants), while Niort is a medium-sized city ( $\sim 60000$ inhabitants), allowing us to investigate the potential impact of the degree of urbanization on nestlings' great tits. Paris is a very good example of historical European city with an extremely dense land occupation (housing development, industrial/commercial sites), and relatively small and isolated city Parks, while Niort is a classical "province" city less densely built with relatively larger city vegetation cover. Accordingly, these differences translated in highly divergent urbanization scores between our study sites as measured in another study (Meillère et al., 2017).

Nests were regularly inspected from March to June to determine laying date, clutch size, incubation date, hatching date of the first egg(s), number of hatchlings and unhatched eggs, brood size (at day 14 post-hatch), and number of successfully fledged nestlings. Only first clutches were used in this study. Data were collected for a total of 424 nestlings, originating from 28 nests in the rural sites (14 in Foljuif and 14 in Chizé) and from 26 nests in the urban sites (10 in Paris and 16 in Niort). Nestlings were captured at the nest when aged 14-days old, except for 2 broods aged 13 (one nest from Paris and one nest from Foljuif) and 4 broods aged 15 (two nests from Paris and two nests from Foljuif). Variation in nestling age being confounded with a pair of urban/rural sites and very low (mean nestling age \pm s.e.: $14.02 \pm 0.34$ ), nestling age was not entered as a covariate in statistical models. Nestling capture spanned from May, 22th to June 10th (mean capture date \pm s.e.: $123.63 \pm$ 7.51; with $121=$ May, 1st), there was no significant difference in phenology among sites $\left[F_{(3,50)}=1.31 p=0.28\right]$. Tarsus length and wing length were measured to the nearest $0.1 \mathrm{~mm}$ with a caliper and a ruler, respectively, and body mass to the nearest $0.25 \mathrm{~g}$ with a Pesola spring balance. A sample of 5-8 yellow feathers was plucked from the center of the yellow breast for each bird, and stored in individual plastic bags in the dark until later color analysis. A blood sample $(20-100 \mu \mathrm{l})$ was taken from the brachial vein in heparinized micro-haematocrit tubes, and centrifuged when back in the lab. Packed red blood cells were separated from plasma and stored at $-20^{\circ} \mathrm{C}$ until later DNA extraction.

\section{Telomere Measurements}

Genomic DNA was extracted from frozen red blood cells using DNeasy Blood and Tissue Kit (Qiagen) according to the manufacturer's protocol. DNA yield and purity were checked 
using a spectrophotometer (Nanodrop ND-1000; Thermo Scientific, USA) according to previous recommendations (Nussey et al., 2014). All sample yields were $>20 \mathrm{ng} \mathrm{\mu l}^{-1}$. Moreover, ranges for absorption of all samples were within an acceptable range (between 1.8 and 2.0 for $260 \mathrm{~nm} / 280 \mathrm{~nm}$ ratio and between 1.9 and 2.2 for $260 \mathrm{~nm} / 230 \mathrm{~nm}$ ratio). Telomeres were measured using real-time quantitative PCR, following a protocol previously validated for birds and successfully used in great tits (Salmón et al., 2016). Briefly, a single-copy gene (glyceraldehyde-3-phosphate dehydrogenase, GAPDH) was amplified using the primers specifically designed for great tits (Atema et al., 2013). Telomeres primers were Tel1b (5'-CGG TTTGTTTGGGTTTGGGTTTGGGTTTGGGTTTGGGTT-3') and Tel2b ( $5^{\prime}$-GGCTTGCCTTACCCTTACCCTTACCCTTAC CCTTACCCT- $3^{\prime}$ ). qPCR for both GAPDH and telomeres was performed using $5 \mathrm{ng}$ of DNA per reaction. After preliminary optimization procedures, the telomere and GAPDH primers were respectively used at a final concentration of 1,000 and 200 nM. To control for the amplifying efficiency of the qPCR, each plate included a standard curve, which consisted of various concentrations of a great tit DNA pool (50-0.08 $\left.\mathrm{ng} \mathrm{mL}^{-1}\right)$. The efficiencies of the qPCR were within the acceptable range for both GAPDH and Telomere (Mean \pm SD; GAPDH: $101.9 \pm 1.09$; Telomere: $96.7 \pm 3.13$ ). Telomere length is expressed relative to the single-copy gene (GAPDH) measured on the same sample of DNA (i.e., T/S ratio, Cawthon, 2002; Salmón et al., 2016). All standard DNA samples were run in duplicates. Moreover, a common sample was run on every plate and the inter-plate $\mathrm{CV}$ in TS ratio was $2.5 \%$. Telomeres measurements were obtained for a subsample of 111 randomly chosen nestlings [number of nestlings (number of nests): Foljuif: $n=36(14)$, Paris: $n=24(10)$, Chizé: $n=30(12)$, Niort: $n=24(9)$ ].

\section{Feather Color Analysis}

Yellow breast feather color was analyzed in the laboratory, using a spectrophotometer (Ocean Optics, IDIL Fibers Optiques, Lannion, France) following previously published methods (Andersson and Prager, 2006), samples being randomly chosen with respect to origin (study site and nest), and among nestlings from the same nest. Feathers were illuminated at an angle of $90^{\circ}$ with a deuterium-tungsten lamp (DH2000), and reflected light was measured at the same angle, with a $200 \mu \mathrm{m}$ fiber-optic reflection probe (QR200-7-SR-BX) connected to the spectrometer (USB2000+) operated using the Spectra Suite software. To exclude ambient light and standardize measuring distance $(3 \mathrm{~mm})$, an opaque black tube was fitted at the end of the measuring probe. Feather color was measured against a black short velvet background regularly cleaned and changed to keep its reflectance constant and equal to 0 . A set of four feathers was randomly chosen among each sample, and piled up to reflect the bird's plumage (Quesada and Senar, 2006), with their rachis superimposed and parallel to each other. Preliminary tests showed that four feathers were sufficient to get reliable and repeatable spectra while keeping the number of feathers collected to a minimum for ethical reasons. Two sets of four feathers were analyzed for each individual with four independent (probe lift up and placed again on the sample) measures per set.
Percentage of reflectance at each $1 \mathrm{~nm}$ interval was calculated between 300 and $700 \mathrm{~nm}$, with respect to white (Spectralon diffuse reflectance Standard, WS-1-SL) and dark references, as $R_{(\lambda)}=100 \times[($ sample-white $) /($ white-dark $)]$. From these values, we calculated two independent and objective parameters to characterize carotenoid-based plumage color. Brightness is the total intensity of light reflected by feathers (spectral intensity), and was calculated as the integral of reflectance over [300, 700] nm (e.g., Endler, 1990; Andersson et al., 1998). Brightness reflects the structural quality of feathers and captures the UV component of carotenoid-based feather reflectance (Shawkey and Hill, 2005; Andersson and Prager, 2006). Plumage brightness has been shown to reflect body condition in this species (Galván, 2010). Carotenoid chroma reflects the carotenoid content of feathers and was calculated as the relative difference between the maximal (plateau at wavelength above $500 \mathrm{~nm}$ ) and minimal (between 445 and $455 \mathrm{~nm}$, corresponding to wavelengths of maximum absorbance of carotenoids) reflectance in the visible part of the spectrum: $\left[\mathrm{R}_{700}-\mathrm{R}_{450}\right] / \mathrm{R}_{700}$ (Örnborg et al., 2002; Andersson and Prager, 2006; Peters et al., 2007). Feather reflectance spectra were obtained by a single observer (MN) for 403 nestlings. Repeatability of measurements calculated as the intra-class correlation coefficient (Lessells and Boag, 1987) was always highly significant $(p<0.0001)$ with the following values: (a) repeatability within sets of feathers: brightness: 0.92 , carotenoid chroma: 0.75 , (b) and repeatability within individuals: brightness: 0.85 , carotenoid chroma: 0.63 . Average values for the 8 measures per nestling were used in subsequent statistical analyses.

\section{Statistical Analyses}

Statistical analyses were run using SAS v9.3 (SAS Institute Inc., Cary, NC, USA). Values are reported as mean \pm s. e.

Generalized linear models were used to investigate variation in clutch size, number of hatchlings and brood size (number of nestlings surviving to the day of capture), as a function of site, including date as a covariate (GENMOD procedure with a Poisson distribution and a log link function).

Mixed linear models (MIXED procedure) were used to analyze variation in nestling phenotype (tarsus length, body mass, wing length, plumage color, and telomere length) with nest as a random effect to account for non-independence of nestlings raised in the same nest and sharing genetic and common rearing environment effects, using an unstructured covariance and REML (Restricted/Residual Maximum Likelihood) estimation method. The Wald test of the covariance parameter assessed whether the variance was significantly structured by the random nest effect. The fixed part of the models initially included the effects of site, date and the interaction between site and date. Models were compared with Akaike's Information Criterion (AIC), and the most parsimonious was retained (lowest AIC, Burnham and Anderson, 1998). Final models including significant differences between sites were followed by comparisons of means or least square means with adjusted values of $p$, using the Tukey-Kramer method. Tests of the residuals for normality and homoscedasticity were used to check the validity of the models; feather brightness and carotenoid chroma were 
log-transformed to meet these constraints. Finally, mixed linear models were also used to investigate whether plumage color and telomere length were related to nestling body mass and growth conditions (date and brood size) and whether telomere length was related to nestling plumage color. As there were significant differences between sites in brood size, nestling body condition and feather carotenoid chroma (see Section Results), these models were run separately for each site to avoid multicollinearity issues (Graham, 2003).

\section{RESULTS}

Clutch size differed significantly among sites $\left[F_{(3,50)}=8.76\right.$, $p=0.03]$ and was significantly greater in Chizé as compared to Paris (Table 1), but there was no difference among sites in the number of hatchlings $\left[F_{(1,50)}=5.35, p=0.15\right]$. Date and its interaction with site were not retained in the final models for clutch size and the number of hatchlings. Brood size, i.e., the number of nestlings surviving to 14-days old, decreased with advancing season $\left[F_{(1,49)}=4.38, p=0.04\right.$, slope estimate \pm s.e.: $-0.008 \pm 0.004]$ and differed among sites $\left[F_{(1,49)}=3.19\right.$, $p=0.03]$, with great tits in Foljuif rearing more nestlings to fledging than in Niort and Paris, and in Chizé as compared to Paris (Table 1).

Nestling growth, i.e., tarsus length, body mass, and wing length, significantly differed among sites (Table 2A, Figure 1): Nestlings were significantly taller (longer tarsi) in the rural site of Foljuif as compared to the other rural site of Chizé, and both urban sites of Niort and Paris. Nestlings were also smaller in Chizé and Niort as compared to Paris (Figure 1A). Nestlings were heavier in the rural site of Foljuif as compared to Chizé, Niort, and Paris (Figure 1B). Wing length was greater both in Foljuif and Paris as compared to Chizé and Niort (Figure 1C). Regarding plumage color, while yellow feather brightness did not differ among sites, there were significant differences in feather carotenoid chroma (Table 2B, Figure 2): yellow feathers were significantly more chromatic in both woodland sites of Foljuif and Chizé as compared to both urban sites of Paris and Niort. Finally, telomere length did not differ among sites (Table 2B,

TABLE 1 | Mean \pm s.e. great tit clutch size (total number of eggs laid), number of hatchlings and brood size (number of nestlings surviving to 14 days old) in the four study sites.

\begin{tabular}{lccc}
\hline Site & Clutch size & Number of hatchlings & Brood size \\
\hline Chizé & $10.14 \pm 0.49$ & $9.00 \pm 0.48$ & $8.14 \pm 0.48$ \\
Foljuif & $9.15 \pm 0.38$ & $8.79 \pm 0.39$ & $8.64 \pm 0.39$ \\
Niort & $9.31 \pm 0.32$ & $8.18 \pm 0.45$ & $7.62 \pm 0.44$ \\
Paris & $8.30 \pm 0.49$ & $7.5 \pm 0.58$ & $6.90 \pm 0.48$ \\
\hline
\end{tabular}

A posteriori comparison of means or Ismeans for differences among sites (see Section Materials and Methods and Results for more details on the models and site main effect) showed that clutch size in Chize differed significantly from that in Paris $(z=2.90$, adj. $p=0.004)$. Brood size in Foljuif differed from that in Niort and Paris $(z=2.12$, adj. $p=$ 0.03 and $z=2.77$, adj. $p=0.006$, respectively), and brood size in Paris differed from that in Chizé $(z=2.09$ adj. $p=0.04$ ). All other comparison were non-significant (all $z<1.35$ and adj. $p>0.17)$.
Figure 3). Nestling growth, plumage color, and telomere length did not vary with season in any site (date and its interaction with site were not retained in the final models).

Yellow feather brightness was not related to nestling growth conditions or body mass in any site (all $F<1.87$ and $p>0.17$ ). Similarly, carotenoid chroma was not related to nestling growth conditions or body mass in Niort and Foljuif (all $F<2.16$ and $p>0.14$, Figures 4B,C). However, carotenoid chroma was positively related to nestling body mass $\left[F_{(1,40)}=8.02, p=0.007\right.$, estimate \pm s.e. $=0.59 \pm 0.02$, Figure $4 \mathrm{D}]$, while a marginal negative relationship was found in Chizé $\left[F_{(1,98)}=3.51, p=0.06\right.$, estimate \pm s.e. $=-0.02 \pm 0.01$, Figure 4A]. In Foljuif and Niort, telomere length was not related to nestling body mass or growth conditions (all $F<0.59$ and $p>0.45$, Figures 5B,C). However, telomere length was positively related to nestling body mass in Chizé $\left[F_{(1,17)}=7.71, p=0.01\right.$, estimate \pm s.e. $\left.=0.02 \pm 0.01\right]$, while the opposite pattern was found in Paris $\left[F_{(1,13)}=5.45\right.$, $p=0.04$, estimate \pm s.e. $=-0.02 \pm 0.01$; Figures 5A,D]. Finally, telomere length was not related to yellow feather color in any site (all $F<4.19$ and $p>0.07$ ).

\section{DISCUSSION}

In this study, we aimed to assess the impact of urbanization on the phenotype and quality of developing offspring by comparing four populations of great tits. To do so, we focused on complementary morphological and molecular components (growth, plumage coloration, and telomere length). According to our predictions, we found that the body size and the carotenoid-based plumage of great tits chicks were affected by urbanization, although the impact of urbanization on body size was only found in the most urbanized site. However, we did not find any strong evidence for an impact of urbanization on telomere length.

\section{Urbanization and Body Size in Nestling Great Tits}

Overall and according to our prediction, we found some support for an effect of urbanization on nestling body size and body mass. In the area of the biggest city (Paris), we specifically found that urban nestlings were smaller and lighter than rural ones (Foljuif). However, we did not find any difference in body size and body mass between urban (Niort) and rural (Chizé) nestlings in the area of the smallest city. Supporting these contradictory patterns, some studies previously found that urban great tit nestlings are smaller than rural ones (Riddington and Gosler, 1995; Eeva et al., 2009; Geens et al., 2009) while others did not report such a difference (Isaksson and Andersson, 2007). All together, these results suggest that the influence of urbanization on growth and body size may only be apparent when the degree of urbanization reaches an upper threshold, or/and when urbanization is associated with specific anthropogenic perturbations that vary from one locality to another (e.g., pollution, Eeva et al., 2009; Geens et al., 2009). Thus, the effect of urbanization on body size may only be minor and non-significant for great tits reared in small to medium-sized city, such as Niort ( $\sim 70,000$ inhabitants) while it may become 
TABLE 2 | Mixed linear models investigating variation in great tit nestlings' phenotype as a function of site and season.

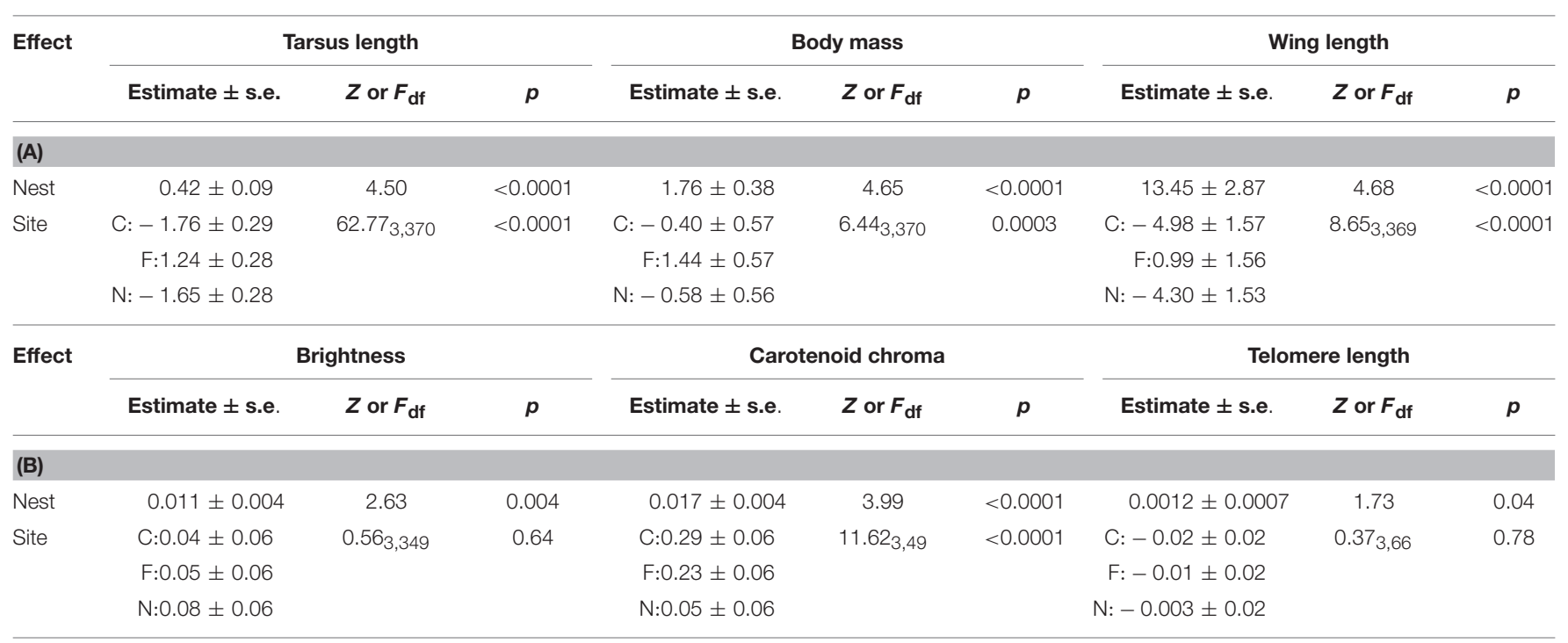

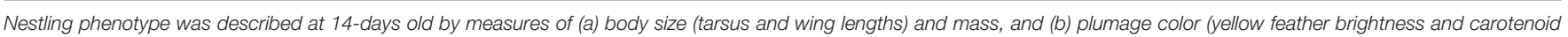

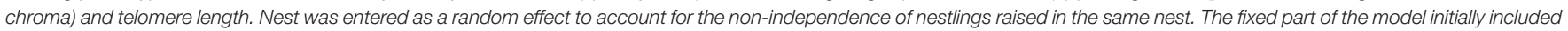

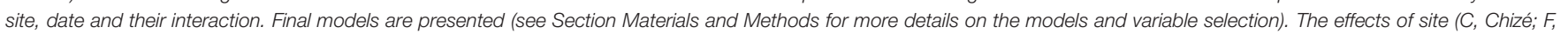
Foljuif; N, Niort; P, Paris) were estimated taking Paris as the level of reference.

important and significant when they grow in large cities, such as Paris (over 2 million inhabitants). Similarly, some studies found an effect of urbanization on body size or growth in other bird species (Heiss et al., 2009; Bókony et al., 2012; Seress et al., 2012), supporting the idea that urbanization can have detrimental effects on growth and development. Interestingly, the influence of urbanization on body size also seems to depend on the degree of urbanization in some of these studies (Bókony et al., 2012; Meillère et al., 2017). For example, Meillère et al. (2017) found that urban house sparrows were not significantly smaller than rural ones when living in a medium-sized city such as Niort, while their body size was significantly reduced when living in bigger cities. To our knowledge, most studies have so far focused on a single pair of sites when comparing urban and rural populations of wild birds. Our study highlights the importance of studying multiple populations all over the urbanization gradient in order to better assess the influence of the degree of urbanization on the morphology of wild vertebrates (see Evans et al., 2009; Bókony et al., 2012; Meillère et al., 2017 for some examples).

At the proximate levels, our results support the idea that developmental conditions may be impoverished in big cities relative to forest areas. Overall, cities are characterized by multiple severe environmental modifications that certainly raise new important developmental constraints for wild vertebrates (Clergeau et al., 2006; McKinney, 2008; Gil and Brumm, 2014). Although, we did not quantify abiotic and biotic constraints in our populations, our study suggests that food abundance could explain the patterns we report because the growth of great tit nestlings has been directly correlated with food supply (NaefDaenzer and Keller, 1999; Mägi et al., 2009, but see Tremblay et al., 2005). Supporting this interpretation, we also found that clutch size and brood size (number of nestlings reaching 14-days old) were generally reduced in cities relative to woodlands.
Interestingly, we found that brood sizes differ between Paris and Foljuif, but not between Niort and Chizé, supporting further the idea that the degree of urbanization may have an impact on the ability of parent great tits to rear numerous young. During the chick-rearing period, great tits rely mainly on arthropods to feed their young and arthropod biomass and diversity is overall reduced in cities (McIntyre, 2000; Helden et al., 2012). Because nestlings rely on protein-rich diet during their development, this arthropod impoverishment is probably a major nutritional constraint for urban developing great tits (McIntyre et al., 2001; Shochat et al., 2004). Supporting this idea, food supplementation experiments have been shown to result in increased body size and nestling survival in urban birds (Zanette et al., 2003; Schoech et al., 2007; Heiss et al., 2009; Meyrier et al., 2017) and crossfostering experiments demonstrated that reduced nestling body size in urban areas is indeed related to the rearing urban environment (e.g., Seress et al., 2012).

\section{Urbanization and Plumage Characteristics}

According to our prediction, we found a strong difference between the plumages of urban and rural nestlings: nestlings from Paris and Niort had less chromatic plumages, indicating their feathers contained less carotenoids (e.g., Peters et al., 2007) than those from Foljuif and Chizé. However, we did not report any effect of urbanization on plumage brightness, i.e., feather structural quality. These results are supported by previous studies that have reported similar results in great tits (Hõrak et al., 2000; Isaksson et al., 2005; Isaksson and Andersson, 2007) and other wild bird species (e.g., Jones et al., 2010; Giraudeau et al., 2015). In wild passerines, the diet seems to be the main factor affecting plumage coloration (Tschirren et al., 2003; Isaksson et al., 2007; Eeva et al., 2009; Giraudeau et al., 2015), and therefore, nestling plumage coloration certainly depends on the ability of parents 

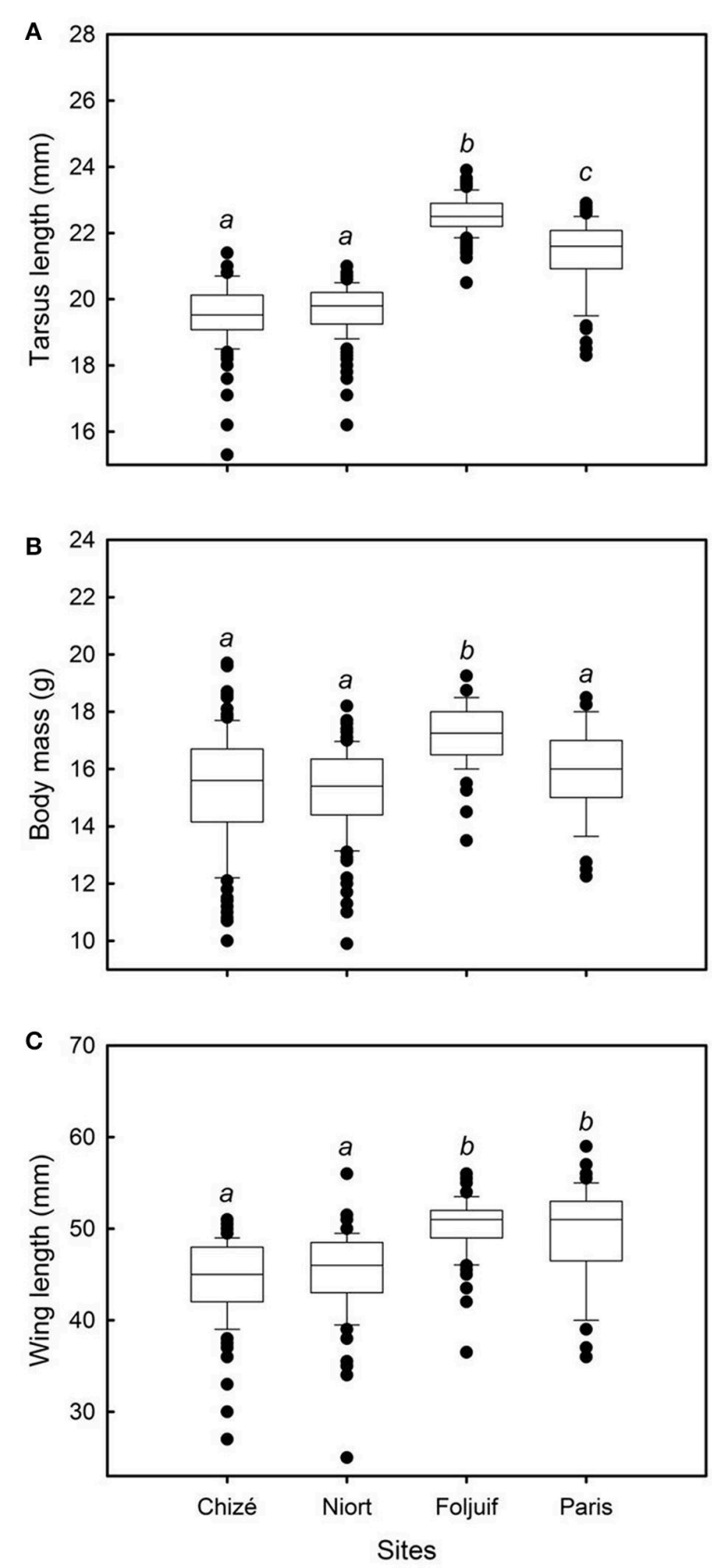

FIGURE 1 | Variation of (A) tarsus length, (B) body mass, and (C) wing length, among breeding sites in great tit nestlings. Nestling tarsus length was significantly greater in the rural site of Foljuif as compared to the other rural site of Chizé, and to both urban sites of Niort and Paris [differences of least squares means: $t_{(d f: 370)}=11.67$, adj. $p<0.0001 ; t_{(d f: 370)}=11.58$, adj. $p<0.0001$; and $t_{(\mathrm{df}: 370)}=4.38$, adj. $p<0.0001$, respectively]. Nestlings were also smaller in Chizé and Niort as compared to Paris $\left[t_{(\mathrm{df}: 370)}=-6.20\right.$, adj. $p<0.0001$; and $t_{(\mathrm{df}: 370)}=-5.95$, adj. $p<0.0001$, respectively]. Nestlings were significantly heavier in the rural site of Foljuif as compared to Chizé, Niort, and Paris [differences of least squares means: $t_{(\mathrm{df}: 370)}=3.56$, adj. $p=0.002$; $t_{(\mathrm{df:}: 370)}=4.03$, adj. $p=0.0004$; and $t_{(\mathrm{df}: 370)}=2.54$, adj. $p=0.05$, respectively]. Wing length was significantly greater both in Foljuif and Paris as compared to Chizé $\left[t_{(\mathrm{df}: 369)}=4.19\right.$, adj. $p=0.0002$; and $t_{(\mathrm{df}: 369)}=3.18$, adj. $p=0.01]$ and Niort $\left[t_{(\mathrm{df}: 369)}=3.84\right.$, adj. $p=0.001 ; t_{(\mathrm{df}: 369)}=2.82$, adj. $p=0.03]$, respectively. Different letters indicate significant differences.

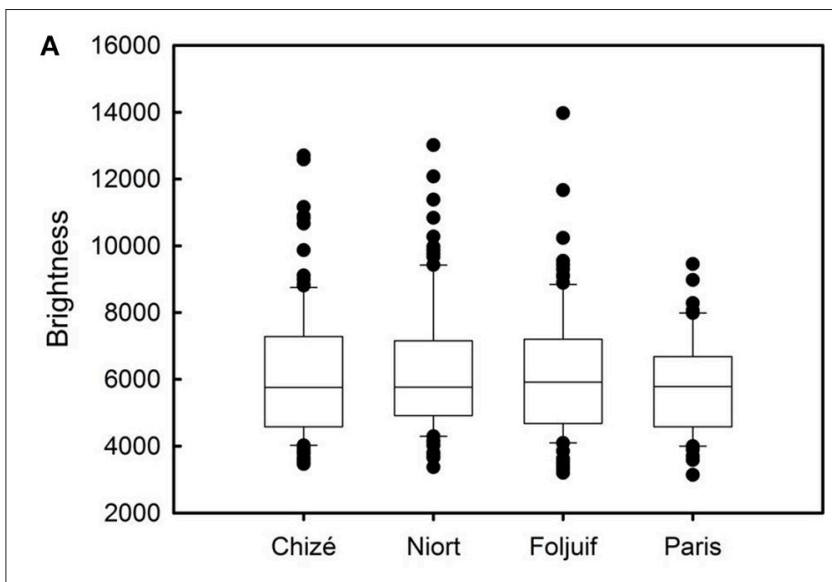

B

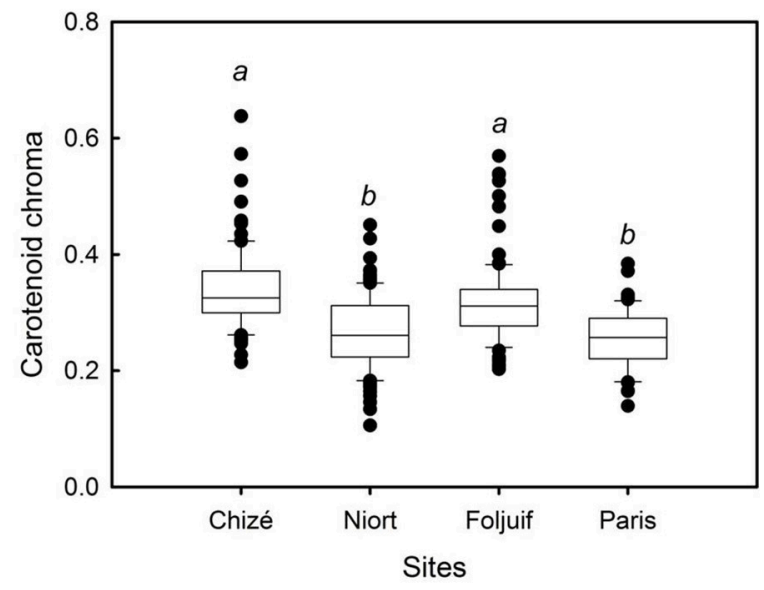

FIGURE 2 | Variation of yellow feather color among breeding sites in great tit nestlings: (A) brightness and (B) carotenoid chroma. Nestling feathers were significantly more chromatic in both woodland sites of Foljuif and Chizé as compared to both urban sites of Paris $\left[t_{(\mathrm{df}: 349)}=3.68\right.$, adj. $p=0.001$; $t_{(\mathrm{df}: 349)}=4.76$, adj. $\left.p<0.0001\right]$ and Niort $\left[t_{(\mathrm{df}: 349)}=3.32\right.$, adj. $p=0.005$; $t_{(\mathrm{df}: 349)}=4.57$, adj. $\left.p<0.0001\right]$, respectively. Different letters indicate significant differences.

to deposit carotenoids into their eggs (Biard et al., 2005, 2007) and to provide their chicks with carotenoid-rich diet (Biard et al., 2006; Isaksson et al., 2006). Our results suggest therefore that carotenoid availability and/or carotenoid uptake is reduced in the urban environment (Isaksson and Andersson, 2007; Isaksson et al., 2007). This interpretation is supported by eco-toxicological studies that were conducted in great tit nestlings: Eeva et al. (1998) and Dauwe and Eens (2008) found that nestlings had a paler plumage when they were raised in more polluted areas, and this effect was mediated by a reduced availability of carotenoidrich diet in polluted areas (Sillanpää et al., 2008; Eeva et al., 2009). Furthermore, we found that the nestlings from Paris had a similar plumage color as those from Niort despite a large difference in the degree of urbanization between these two cities. Interestingly, this suggests that nestling plumage coloration is not strongly dependent on the degree of urbanization of a city, and more importantly that carotenoid availability or/and uptake by nestlings may not differ between medium-sized and large cities. 


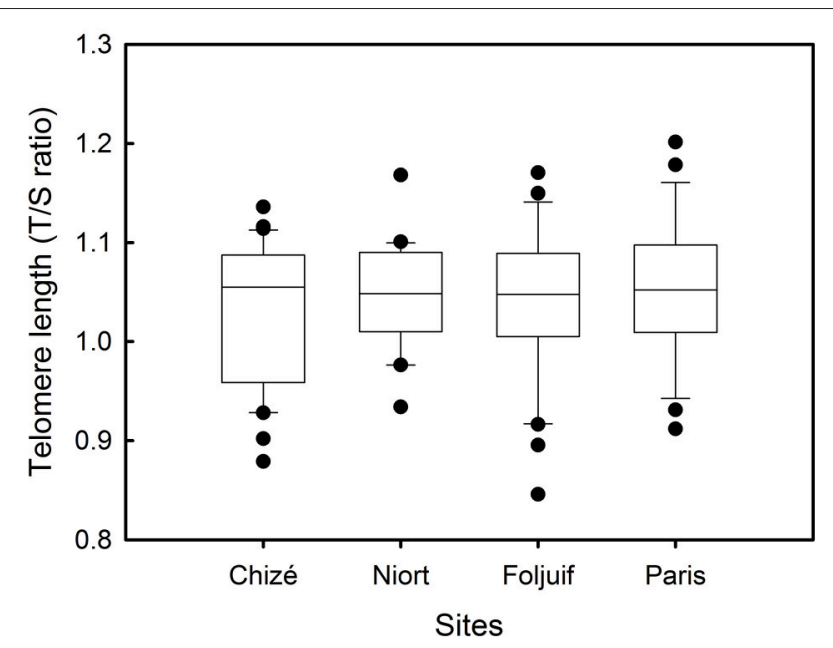

FIGURE 3 | Variation of telomere length among breeding sites in great tit nestlings reared in Chizé (woodland) and Niort (urban), Foljuif (woodland), and Paris (urban).

The diet of nestlings surely differs to a large extent between urban and rural habitats (Isaksson and Andersson, 2007) as shown by contrasted body composition between urban and rural wild birds (e.g., yolk and plasma fatty acids, Andersson et al., 2015; Toledo et al., 2016). However, our results also suggest that the carotenoid availability and/or uptake may only slightly differ within a given habitat type (e.g., between different urban habitats, between different forests). To our knowledge, our study is the first to compare the plumage coloration of two urban populations, but another study did not report any difference in plumage coloration between woodlands differing in size (Ferns and Hinsley, 2008). Similarly, egg yolk fatty acid composition did not significantly differ between different types of woodlands, confirming therefore that the diet may not dramatically differ between different types of woodlands (Toledo et al., 2016).

We did not find any correlation between body mass and plumage coloration in Niort, Foljuif and Chizé (although the relationship was marginally significant in Chizé for feather carotenoid chroma). This suggests that growth and plumage color are relatively independent and may be governed by different pathways, as previously suggested by Hõrak et al. (2000). Actually, carotenoid availability appears as the main driver of plumage coloration whereas structural growth is probably rather related to nutritional conditions that could be independent of carotenoid contents. In contrast to Niort, Chizé, and Foljuif, body mass was positively correlated with plumage carotenoid chroma in Paris (i.e., the most urbanized population in our study). In Paris, the largest chicks were also the most colorful. This suggests that growth and plumage coloration might be simultaneously reduced when nutritional conditions are especially constraining (see also Senar et al., 2003). Supporting the idea that plumage coloration can be related to the nutritional status of individuals under some circumstances, previous studies found that the plumage of infected individuals was paler than that of healthy ones (Møller et al., 2000; Hõrak et al., 2001). Similarly, Tschirren et al. (2003) experimentally demonstrated a positive relationship between growth conditions and plumage coloration in great tit nestlings. Therefore, our study highlights a complex and context-dependent relationship between growth and plumage coloration in developing nestlings (Hõrak et al., 2000; Tschirren et al., 2003; Isaksson and Andersson, 2007). Under constraining environmental conditions, parents may decide to allocate most of the food and most of the carotenoid-rich items to the healthier nestlings, resulting therefore in a positive relationship between growth and plumage coloration.

In the highly-urbanized site (Paris), we clearly found that the development of great tit nestlings was detrimentally impacted (smaller structural size and paler plumage). Although structural growth was not slowed down in the moderately-urbanized site (Niort), we found that plumage color was paler relative to rural nestlings. Because both structural size and plumage color have been related to subsequent performances (e.g., Hõrak et al., 2001; Naef-Daenzer et al., 2001; Blount et al., 2003), our study highlights that urbanization may have multiple effects on developing wild birds. Further studies are now needed to better assess how these urban-related phenotypic modifications translate into fitness consequences.

\section{Urbanization and Telomere Length}

Contrary to our prediction, we did not find any effect of urbanization on telomere length in 14-days old great tit nestlings. Thus, we did not detect any difference in telomere length between the four populations (Paris, Niort, Foljuif, Chizé), suggesting no impact of urbanization on telomere length in nestling great tits. Conversely, Salmón et al. (2016) found that telomeres of urban great tit nestlings were shorter than those of rural nestlings and these findings were recently supported by another ecotoxicological study (Stauffer et al., 2017). However, Stauffer et al. (2017) also found that telomere length was not affected by urban-like pollution in nestlings from another passerine species, the pied flycatcher (Ficedula hypoleuca). To our knowledge, the impact of urbanization on telomere dynamics has so far rarely been studied in wild vertebrates, and taken all together, these studies suggest that the influence of urbanization on telomere length may depend on the species but also on the environmental characteristics of a given city. It also indicates that urbanization does not necessarily translate into significantly shorter telomeres in wild passerines.

Other hypotheses could also explain why urbanization affects telomere length in some studies but not others. First, these differences could result from regional differences in environmental conditions. In our study, we captured nestlings from four sites (two cities and two forests) that were located in Western Europe. In contrast, Salmón et al. (2016) and Stauffer et al. (2017) studied Northern populations that were located in Scandinavia. Regional differences in life-history strategies or environmental conditions could therefore potentially account for these contrasted results. Second, Niort is a medium-sized city, and thus urbanization may not have been intense enough to induce a strong effect on telomere length in that site. This hypothesis is however quite unlikely because we also did not detect any difference in telomere length in Paris, which is one 

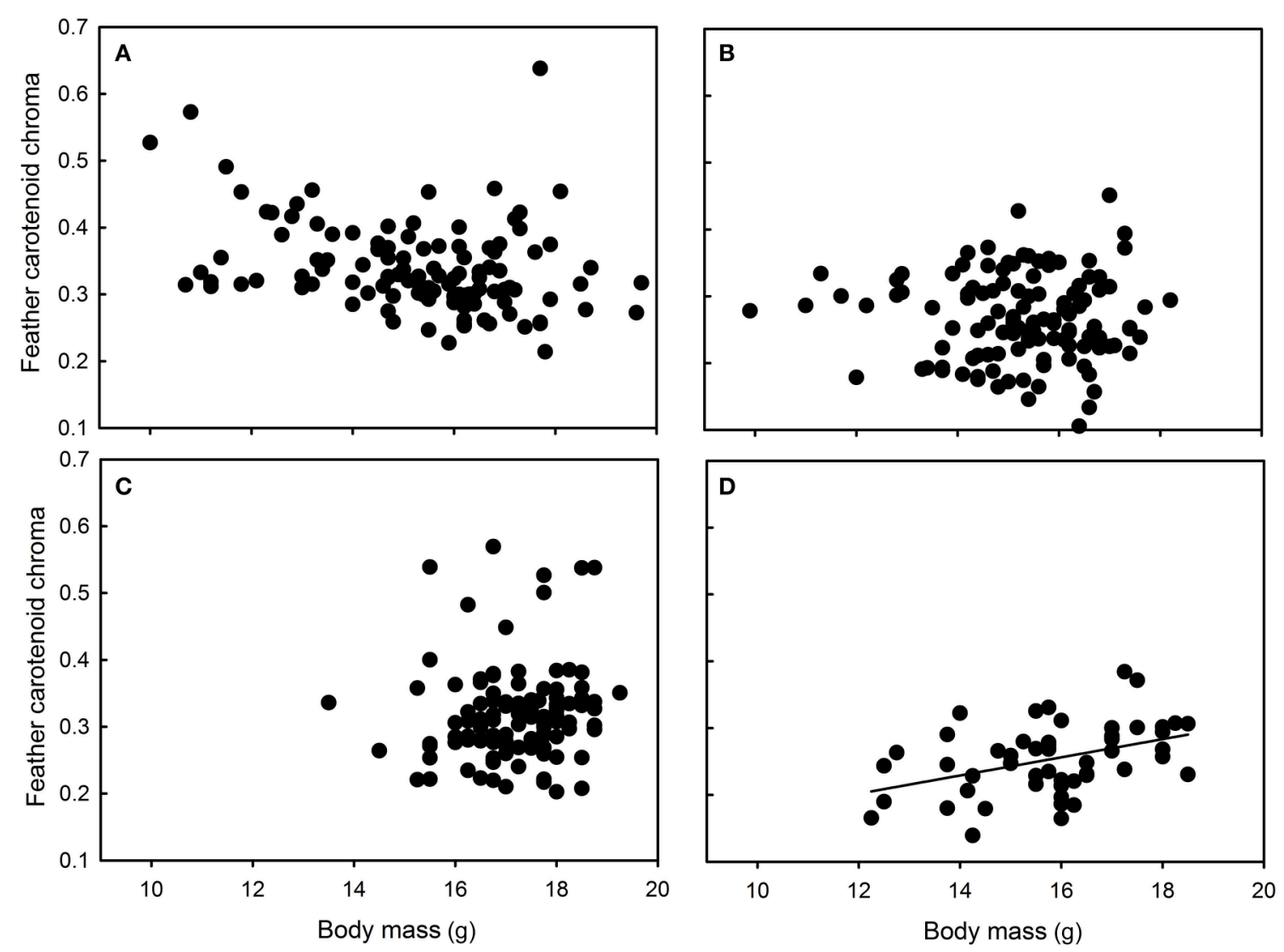

FIGURE 4 | Relationships between feather carotenoid chroma and body mass in great tit nestlings reared in (A) Chizé and (B) Niort, (C) Foljuif, and (D) Paris. For information, the marginally negative relationship in Chizé (see text for details), turned significant when the seemingly outlier data point is excluded $\left[F_{(1,97)}=8.38\right.$, $p=0.005$, estimate \pm s.e. $=-0.03 \pm 0.01$ ). There was however no biological or methodological reason to exclude a posteriori this nestling from the data set.

of the most densely inhabited city in Europe, as compared to the other three sites studied. Moreover, Salmón et al., 2016) sampled great tits in Malmö, which is much smaller than Paris. Thirdly, selection processes could have masked a potential effect of urbanization on telomere length (Haussmann and Mauck, 2008). Urbanization is known to be associated with intense brood competition, and thus with brood reduction (reviewed in Chamberlain et al., 2009). Accordingly, we found that brood sizes were overall smaller in cities (Paris and Niort) relative to woodlands (Foljuif and Chizé), although the difference was marginally significant between Niort and Chizé. This brood reduction means that most of the costs are probably borne by a few nestlings while the others are only slightly disadvantaged. Supporting this hypothesis, Stier et al. (2015) found in great tits that the last-hatched nestling has shorter telomeres than its siblings at fledging. Therefore, reduced telomere length could have only occurred in the weakest nestlings that did not reach 14-days old, and were therefore not sampled in our study. This would however mean that urbanization translates into the production of fewer offspring and not necessarily into the production of fledglings with shorter telomeres. Lastly, we may also raise the hypothesis that the telomere length of nestlings may have been preserved at the cost of growth and plumage coloration in the cities we studied (Paris and Niort). Telomere attrition is known to result from oxidative stress (Monaghan, 2014) that is associated with rapid growth (Geiger et al., 2012) and reduced antioxidant protection in wild birds (Monaghan et al., 2009). Because the nestlings from Paris were smaller relative to those from Foljuif, the growth of the nestlings from Paris could have been reduced to limit the oxidative damages. Similarly, most carotenoids could have been allocated to antioxidant functions, and thus telomere protection, at the cost of plumage coloration in urbanized sites (Niort and Paris) although the antioxidant role of carotenoids is debated (Costantini, 2008; Isaksson and Andersson, 2008).

We found that telomere length was not related to growth in Niort and Foljuif, suggesting that developmental nutritional deficit does not necessarily translate into shorter telomeres. However, we found a positive relationship between growth and telomere length in Chizé, suggesting that higher quality nestlings also had longer telomeres. This finding is supported by several studies that have reported a positive relationship between body size and telomere length in chicks or young individuals (Caprioli et al., 2013; Angelier et al., 2015; Parolini 

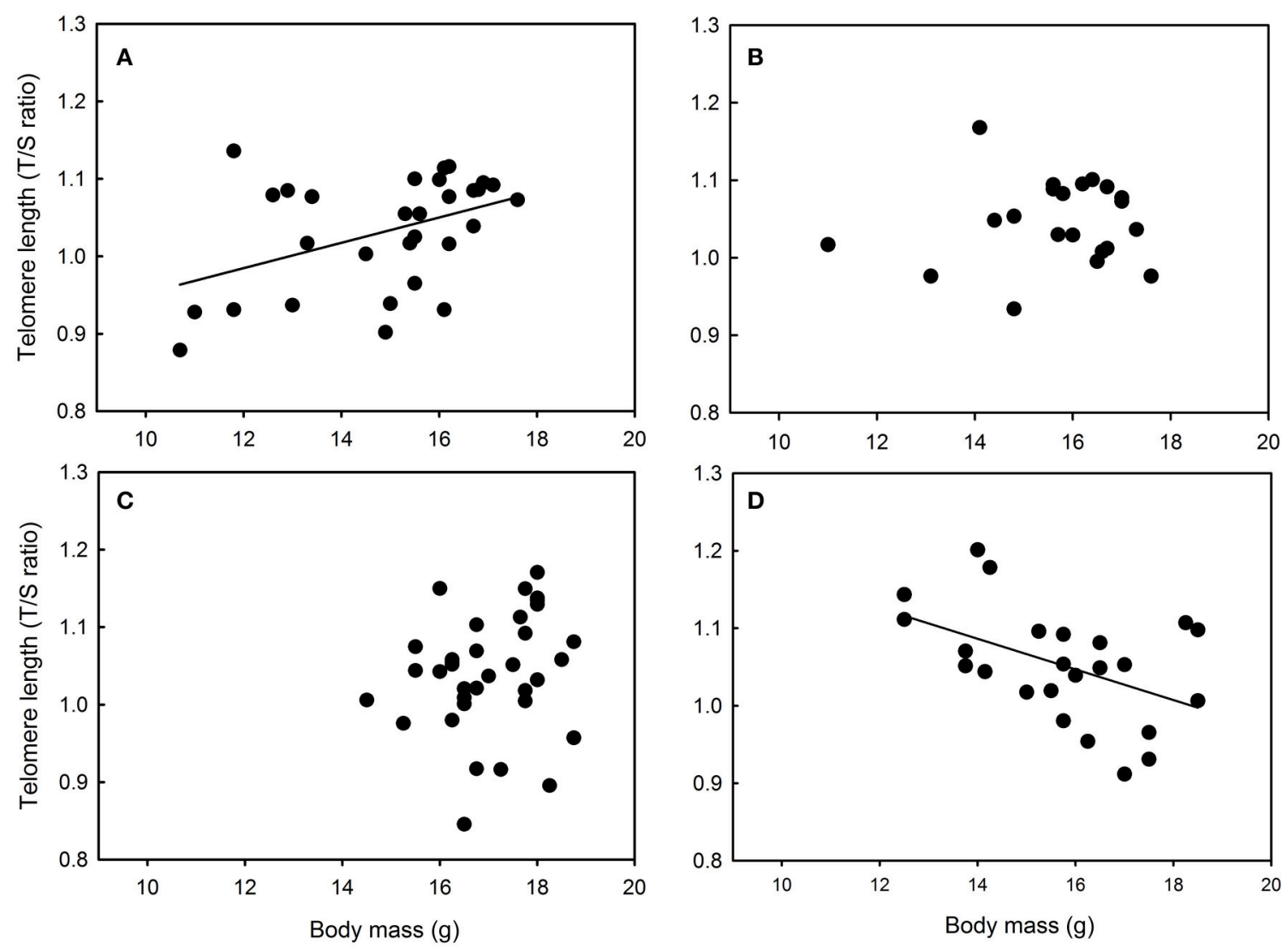

FIGURE 5 | Relationships between telomere length and body mass in great tit nestlings reared in (A) Chizé and (B) Niort, (C) Foljuif, and (D) Paris (see text for details of the statistics).

et al., 2015; Mizutani et al., 2016) and it suggests that long telomeres may be a proxy of good nutritional conditions, at least under some circumstances. Surprisingly, we found the opposite pattern in Paris where larger individuals had shorter telomeres. This suggests that structural growth may be made at the expense of telomere protection in highly urbanized populations. Accordingly, previous studies have found that accelerated growth can be associated with oxidative stress and telomere attrition in wild birds (Geiger et al., 2012; Stier et al., 2015). Overall, it remains however unclear why the relationship between telomere length and body size/growth differs to such extent between sites. It emphasizes that the link between urbanization, environmental conditions and telomere dynamics is complex and deserves further studies.

\section{Regional Differences in Nestlings' Morphology and Reproductive Output}

Interestingly, we reported a large regional difference in body size between the Paris (Paris and Foljuif) and the Niort geographical areas (Niort and Chizé). Thus, the nestlings from the Paris area (Paris and Foljuif) were overall larger and bigger than those from the Niort area (Niort and Chizé). Although, this difference could result from a different way of measuring the nestlings between sites, this is quite unlikely because all the ringers in France are trained to use similar measurement techniques. Moreover, we found exactly the same pattern for tarsus length and wing length, but also for body mass that is not subject to a handler effect (body mass is measured with an electronic or spring scale). This supports therefore the idea that these differences do not result from different measurements techniques. However, we cannot totally exclude the possibility that some differences in morphological data have to do with variation in measurement techniques Despite this potential bias, our result is supported by the Bergman's rule (i.e., selection of larger body size as temperature decreases, and thus as latitude increases, Ashton, 2002) and by previous studies that have also reported an increase in body size as latitude increases in this species (Snow, 1954; Encabo et al., 2002). Alternatively, other explanations could also be involved in these structural differences between the two areas. For instance, predation risk, food resources and more generally environmental conditions are known to be associated with regional variations in body size (reviewed in Blanckenhorn, 2000). In our study, such hypothesis could explain the differences in body size between populations. For example, environmental conditions (food resources) could have been particularly favorable to nestlings' development (e.g., growth) in Foljuif relative to our other study populations. 
More generally, this variation in body size might have important implications when focusing on the impact of urbanization on growth and nestlings' phenotypes because growing a larger structural size requires necessarily more energy and this may be especially challenging in an impoverished habitat, such as the urban one. Consequently, it suggests that the influence of urbanization on reproduction and nestlings' phenotypes might differ between populations of great tits. So far, the influence of urbanization on nestlings' phenotypes of great tits has mainly been studied in Northern environments (e.g., Riddington and Gosler, 1995; Isaksson and Andersson, 2007; Eeva et al., 2009; Geens et al., 2009). Further studies should therefore focus on multiple environmental conditions (populations spread over a large geographic range) in order to better assess the impact of urbanization not only on nestlings and reproductive performances, but also on adult wild birds.

\section{AUTHOR CONTRIBUTIONS}

CB: Conceived the research, conducted field work, analyzed data, wrote the manuscript. FB: Conceived the research, conducted field work. AM: Conducted field work, provided comments on the manuscript. BM: Conducted field work. $\mathrm{MN}$ : Analyzed feather color. SR: Conducted molecular lab work. MV: Conducted field work, provided comments on the

\section{REFERENCES}

Andersson, M. N., Wang, H.-L., Nord, A., Salmon, P., and Isaksson, C. (2015). Composition of physiologically important fatty acids in great tits differs between urban and rural populations on a seasonal basis. Front. Ecol. Evol. 3:93. doi: 10.3389/fevo.2015.00093

Andersson, S., and Prager, M. (2006). "Quantiying colors," in Bird Coloration. I. Mechanisms and Measurement, eds G. E. Hill and K. J. McGraw (Cambridge, MA: Harvard University Press), 41-89.

Andersson, S., Örnborg, J., and Andersson, M. (1998). Ultraviolet sexual dimorphism and assortative mating in blue tits. Proc. R. Soc. B Biol. Sci. 265, 445-450. doi: 10.1098/rspb.1998.0315

Angelier, F., Vleck, C. M., Holberton, R. L., and Marra, P. P. (2015). Bill size correlates with telomere length in male american redstarts. J. Ornithol. 156, 525-531. doi: 10.1007/s10336-015-1158-9

Ashton, K. G. (2002). Patterns of within-species body size variation of birds: strong evidence for bergmann's rule. Global Ecol. Biogeogr. 11, 505-523. doi: 10.1046/j.1466-822X.2002.00313.x

Atema, E., Oers, K. V., and Verhulst, S. (2013). Gapdh as a control gene to estimate genome copy number in great tits, with cross-amplification in blue tits. Ardea 101, 49-54. doi: 10.5253/078.101.0107

Audet, J.-N., Ducatez, S., and Lefebvre, L. (2015). The town bird and the country bird: problem solving and immunocompetence vary with urbanization. Behav. Ecol. 27, 637-644. doi: 10.1093/beheco/arv201

Ausprey, I. J., and Rodewald, A. D. (2011). Postfledging survivorship and habitat selection across a rural-to-urban landscape gradient. Auk 128, 293-302. doi: 10.1525/auk.2011.10158

Bailly, J., Scheifler, R., Berthe, S., Clément-Demange, V.-A., Leblond, M., Pasteur, B., et al. (2016). From eggs to fledging: negative impact of urban habitat on reproduction in two tit species. J. Ornithol. 157, 377-392. doi: 10.1007/s10336-015-1293-3

Barrett, E. L. B., Burke, T. A., Hammers, M., Komdeur, J., and Richardson, D. S. (2013). Telomere length and dynamics predict mortality in a wild longitudinal study. Mol. Ecol. 22, 249-259. doi: 10.1111/mec.12110 manuscript. FA: Conceived the research, conducted field work, wrote the manuscript.

\section{ACKNOWLEDGMENTS}

We are grateful to the ANR (URBASTRESS, ANR-16-CE020004-01), the Centre National de la Recherche Scientifique (CNRS), the University of La Rochelle (ULR), the Région Poitou-Charentes, the Conseil Départemental des Deux-Sèvres (DC 79), the Contrat Plan Etat region (CPER ECONAT), and Sorbonne Universités-University Pierre et Marie Curie Paris 06 (Émergence-UPMC EME 1110) for funding this research. This work conforms to French legal requirements, including those relating to conservation and welfare, and was conducted under ringing licenses and authorizations for blood and feather sampling from the CRBPO (National Museum of Natural History) to CB and FA (research programs \# 537 and 664, respectively). The protocol was approved by the COMETHEA ethical committee (CE2013-03). We would also like to acknowledge the support of the National Forest Office (ONF) and the cities of Paris and Niort, in allowing us to survey tit populations breeding in state-owned forest and city parks, respectively. We also thank all the students for their help in conducting fieldwork and Janice Duru for her help in the lab with feather color analyses.

Berthouly, A., Helfenstein, F., Tanner, M., and Richner, H. (2008). Sexrelated effects of maternal egg investment on offspring in relation to carotenoid availability in the great tit. J. Anim. Ecol. 77, 74-82. doi: 10.1111/j.1365-2656.2007.01309.x

Biard, C., Surai, P. F., and Møller, A. P. (2005). Effects of carotenoid availability during laying on reproduction in the blue tit. Oecologia 144, 32-44. doi: 10.1007/s00442-005-0048-x

Biard, C., Surai, P. F., and Møller, A. P. (2006). Carotenoid availability in diet and phenotype of blue and great tit nestlings. J. Exp. Biol. 209, 1004-1015. doi: 10.1242/jeb.02089

Biard, C., Surai, P. F., and Møller, A. P. (2007). An analysis of pre- and posthatching maternal effects mediated by antioxidants in the blue tit. J. Evol. Biol. 20, 326-339. doi: 10.1111/j.1420-9101.2006.01194.x

Bichet, C., Scheifler, R., Courdassier, M., Julliard, R., Sorci, G., and Loiseau, C. (2013). Urbanization, trace metal pollution, and malaria prevalence in the house sparrow. PLoS ONE 8:e53866. doi: 10.1371/journal.pone.0053866

Blackburn, E. H. (2000). Telomere states and cell fates. Nature 408, 53-56. doi: $10.1038 / 35040500$

Blanckenhorn, W. U. (2000). The evolution of body size: what keeps organisms small? Q. Rev. Biol. 75, 385-407. doi: 10.1086/393620

Blount, J. D., Metcalfe, N. B., Arnold, K. E., Surai, P. F., Devevey, G. L., and Monaghan, P. (2003). Neonatal nutrition, adult antioxidant defences and sexual attractiveness in the zebra finch. Proc. R. Soc. B Biol. Sci. 270, 1691-1696. doi: $10.1098 / \mathrm{rspb} .2003 .2411$

Bókony, V., Seress, G., Nagy, S., Lendvai, Á. Z., and Liker, A. (2012). Multiple indices of body condition reveal no negative effect of urbanization in adult house sparrows. Landsc. Urban Plan. 104, 75-84. doi: 10.1016/j.landurbplan.2011.10.006

Bonier, F. (2012). Hormones in the city: endocrine ecology of urban birds. Horm. Behav. 61, 763-772. doi: 10.1016/j.yhbeh.2012.03.016

Both, C., Artemyev, A. V., Blaauw, B., Cowie, R. J., Dehuijzen, A. J., Eeva, T., et al. (2004). Large-scale geographical variation confirms that climate change causes birds to lay earlier. Proc. R. Soc. B Biol. Sci. 271, 1657-1662. doi: $10.1098 / \mathrm{rspb} .2004 .2770$ 
Burnham, K. P., and Anderson, D. R. (1998). Model Selection And Inference: A Practical Information-Theoretic Approach. New York, NY: Springer Verlag.

Caprioli, M., Romano, M., Romano, A., Rubolini, D., Motta, R., Folini, M., et al. (2013). Nestling telomere length does not predict longevity, but covaries with adult body size in wild barn swallows. Biol. Lett. 9:20130340. doi: 10.1098/rsbl.2013.0340

Cawthon, R. M. (2002). Telomere measurement by quantitative pcr. Nucleic Acids Res. 30, e47-e47. doi: 10.1093/nar/30.10.e47

Chace, J. F., and Walsh, J. J. (2006). Urban effects on native avifauna: a review. Landsc. Urban Plan. 74, 46-69. doi: 10.1016/j.landurbplan.2004.08.007

Chamberlain, D. E., Cannon, A. R., Toms, M. P., Leech, D. I., Hatchwell, B. J., and Gaston, K. J. (2009). Avian productivity in urban landscapes: a review and meta-analysis. Ibis 151, 1-18. doi: 10.1111/j.1474-919X.2008.00899.x

Clergeau, P., Croci, S., Jokimäki, J., Kaisanlahti-Jokimäki, M.-L., and Dinetti, M. (2006). Avifauna homogenisation by urbanisation: analysis at different european latitudes. Biol. Conserv. 127, 336-344. doi: 10.1016/j.biocon. 2005.06.035

Costantini, D. (2008). Oxidative stress in ecology and evolution: lessons from avian studies. Ecol. Lett. 11, 1238-1251. doi: 10.1111/j.1461-0248.2008.01246.x

Croci, S., Butet, A., and Clergeau, P. (2008). Does urbanization filter birds on the basis of their biological traits. Condor 110, 223-240. doi: $10.1525 /$ cond.2008.8409

Crooks, K. R., Suarez, A. V., and Bolger, D. T. (2004). Avian assemblages along a gradient of urbanization in a highly fragmented landscape. Biol. Conserv. 115, 451-462. doi: 10.1016/S0006-3207(03)00162-9

Cucco, M., Guasco, B., Malacarne, G., and Ottonelli, R. (2006). Effects of beta-carotene supplementation on chick growth, immune status and behaviour in the grey partridge, Perdix perdix. Behav. Process. 73, 325-332. doi: 10.1016/j.beproc.2006.08.002

Dauwe, T., and Eens, M. (2008). Melanin- and carotenoid-dependent signals of great tits (Parus major) relate differently to metal pollution. Naturwissenschaften 95, 969-973. doi: 10.1007/s00114-008-0400-1

Deviche, P., and Davies, S. (2014). "Reproductive phenology of urban birds: Environmental cues and mechanisms. Avian urban ecology: Behavioural and physiological adaptations," in Avian Urban Ecology: Behavioural and Physiological Adaptations, eds D. Gil and H. Brumm (Oxford: Oxford University Press), 98-115.

Dominoni, D., Quetting, M., and Partecke, J. (2013). Artificial light at night advances avian reproductive physiology. Proc. R. Soc. B Biol. Sci. 280:20123017. doi: 10.1098/rspb.2012.3017

Duckworth, R. A. (2014). "Human-induced changes in the dynamics of species coexistence: An example with two sister species," in Avian Urban Ecology: Behavioural and Physiological Adaptations, eds D. Gil and H. Brumm (Oxford: Oxford University Press), 181-191.

Eeva, T., Lehikoinen, E., and Rönkä, M. (1998). Air pollution fades the plumage of the great tit. Funct. Ecol. 12, 607-612. doi: 10.1046/j.1365-2435.1998.00221.x

Eeva, T., Sillanpää, S., and Salminen, J.-P. (2009). The effects of diet quality and quantity on plumage colour and growth of great tit Parus major nestlings: a food manipulation experiment along a pollution gradient. J. Avian Biol. 40, 491-499. doi: 10.1111/j.1600-048X.2008.04535.x

Encabo, S. I., Barba, E., Gil-Delgado, J., and Monrós, J. S. (2002). Geographical variation in egg size of the great tit Parus major: a new perspective. Ibis 144, 623-631. doi: 10.1046/j.1474-919X.2002.00099.x

Endler, J. A. (1990). On the measurement and classification of colour in studies of animal colour patterns. Biol. J. Linnean Soc. 41, 315-352. doi: 10.1111/j.1095-8312.1990.tb00839.x

Engels, S., Schneider, N.-L., Lefeldt, N., Hein, C. M., Zapka, M., Michalik, A., et al. (2014). Anthropogenic electromagnetic noise disrupts magnetic compass orientation in a migratory bird. Nature 509, 353-356. doi: 10.1038/nature13290

Evans, K. L., Chamberlain, D. E., Hatchwell, B. J., Gregory, R. D., and Gaston, K. J. (2011). What makes an urban bird? Glob. Chang. Biol. 17, 32-44. doi: 10.1111/j.1365-2486.2010.02247.x

Evans, K. L., Gaston, K. J., Sharp, S. P., McGowan, A., and Hatchwell, B. J. (2009). The effect of urbanisation on avian morphology and latitudinal gradients in body size. Oikos 118, 251-259. doi: 10.1111/j.1600-0706.2008.17092.x

Fairlie, J., Holland, R., Pilkington, J. G., Pemberton, J. M., Harrington, L., and Nussey, D. H. (2016). Lifelong leukocyte telomere dynamics and survival in a free-living mammal. Aging Cell 15, 140-148. doi: 10.1111/acel.12417
Fernández-Juricic, E. (2002). Can human disturbance promote nestedness? A case study with breeding birds in urban habitat fragments. Oecologia 131, 269-278. doi: 10.1007/s00442-002-0883-y

Ferns, P. N., and Hinsley, S. A. (2008). Carotenoid plumage hue and chroma signal different aspects of individual and habitat quality in tits. Ibis 150, 152-159. doi: 10.1111/j.1474-919X.2007.00759.x

Fischer, J. D., Cleeton, S. H., Lyons, T. P., and Miller, J. R. (2012). Urbanization and the predation paradox: the role of trophic dynamics in structuring vertebrate communities. Bioscience 62, 809-818. doi: 10.1525/bio. 2012.62.9.6

Fitze, P. S., Kölliker, M., and Richner, H. (2003). Effects of common origin and common environment on nestling plumage coloration in the great tit (Parus major). Evolution 57, 144-150. doi: 10.1111/j.0014-3820.2003.tb00222.x

Fuller, R. A., Warren, P. H., and Gaston, K. J. (2007). Daytime noise predicts nocturnal singing in urban robins. Biol. Lett. 3, 368-370. doi: 10.1098/rsbl.2007.0134

Galbraith, J. A., Beggs, J. R., Jones, D. N., and Stanley, M. C. (2015). Supplementary feeding restructures urban bird communities. Proc. Natl. Acad. Sci. U.S.A. 112, E2648-E2657. doi: 10.1073/pnas.1501489112

Galván, I. (2010). Plumage coloration can be perceived as a multiple condition-dependent signal by great tits Parus major. Ibis 152, 359-367. doi: 10.1111/j.1474-919X.2009.00999.x

Gebhardt-Henrich, S., and Richner, H. (1998). Causes of growth variation and its consequences for fitness. Oxford Ornithol. Ser. 8, 324-339.

Geens, A., Dauwe, T., and Eens, M. (2009). Does anthropogenic metal pollution affect carotenoid colouration, antioxidative capacity and physiological condition of great tits (Parus major)? Comp. Biochem. Physiol. Part C Toxicol. Pharmacol. 150, 155-163. doi: 10.1016/j.cbpc.2009.04.007

Geiger, S., Le Vaillant, M., Lebard, T., Reichert, S., Stier, A., Le Maho, Y., et al. (2012). Catching-up but telomere loss: half-opening the black box of growth and ageing trade-off in wild king penguin chicks. Mol. Ecol. 21, 1500-1510. doi: 10.1111/j.1365-294X.2011.05331.x

Gil, D., and Brumm, H. (Eds.). (2014). Avian Urban Ecology: Behavioural and Physiological Adaptations. Oxford: Oxford University Press.

Giraudeau, M., and McGraw, K. J. (2014). Physiological correlates of urbanization in a desert songbird. Integr. Comp. Biol. 54, 622-632. doi: 10.1093/icb/icu024

Giraudeau, M., Chavez, A., Toomey, M. B., and McGraw, K. J. (2015). Effects of carotenoid supplementation and oxidative challenges on physiological parameters and carotenoid-based coloration in an urbanization context. Behav. Ecol. Sociobiol. 69, 957-970. doi: 10.1007/s00265-015-1908-y

Giraudeau, M., Mousel, M., Earl, S., and McGraw, K. (2014). Parasites in the city: degree of urbanization predicts poxvirus and coccidian infections in house finches (Haemorhous mexicanus). PLoS ONE 9, e86747. doi: 10.1371/journal.pone.0086747

Graham, M. H. (2003). Confronting multicollinearity in ecological multiple regression. Ecology 84, 2809-2815. doi: 10.1890/02-3114

Grimm, N. B., Faeth, S. H., Golubiewski, N. E., Redman, C. L., Wu, J., Bai, X., et al. (2008). Global change and the ecology of cities. Science 319, 756-760. doi: 10.1126/science.1150195

Harrison, T., Smith, J., Martin, G., Chamberlain, D., Bearhop, S., Robb, G., et al. (2010). Does food supplementation really enhance productivity of breeding birds? Oecologia 164, 311-320. doi: 10.1007/s00442-010-1645-x

Haussmann, M. F., and Mauck, R. A. (2008). Telomeres and longevity: testing an evolutionary hypothesis. Mol. Biol. Evol. 25, 220-228. doi: 10.1093/molbev/msm244

Heidinger, B. J., Blount, J. D., Boner, W., Griffiths, K., Metcalfe, N. B., and Monaghan, P. (2012). Telomere length in early life predicts lifespan. Proc. Natl. Acad. Sci. U.S.A. 109, 1743-1748. doi: 10.1073/pnas.1113306109

Heiss, R. S., Clark, A. B., and McGowan, K. J. (2009). Growth and nutritional state of american crow nestlings vary between urban and rural habitats. Ecol. Appl. 19, 829-839. doi: 10.1890/08-0140.1

Helden, A. J., Stamp, G. C., and Leather, S. R. (2012). Urban biodiversity: comparison of insect assemblages on native and non-native trees. Urban Ecosyst. 15, 611-624. doi: 10.1007/s11252-012-0231-x

Hõrak, P., Ots, I., Vellau, H., Spottiswoode, C., and Møller, A. P. (2001). Carotenoid-based plumage coloration reflects hemoparasite infection and local survival in breeding great tits. Oecologia 126, 166-173. doi: $10.1007 / \mathrm{s} 004420000513$ 
Hõrak, P., Vellau, H., Ots, I., and Møller, A. P. (2000). Growth conditions affect carotenoid-based plumage coloration of great tit nestlings. Naturwissenschaften 87, 460-464. doi: 10.1007/s001140050759

Ibáñez-Álamo, J. D., and Soler, M. (2010). Does urbanization affect selective pressures and life-history strategies in the common blackbird (Turdus merula L.)? Biol. J. Linnean Soc. 101, 759-766. doi: 10.1111/j.1095-8312.2010.01543.x

Isaksson, C. (2009). The chemical pathway of carotenoids: from plants to birds. Ardea 97, 125-128. doi: 10.5253/078.097.0116

Isaksson, C. (2010). Pollution and its impact on wild animals: a meta-analysis on oxidative stress. Ecohealth 7, 342-350. doi: 10.1007/s10393-010-0345-7

Isaksson, C., and Andersson, S. (2007). Carotenoid diet and nestling provisioning in urban and rural great tits Parus major. J. Avian Biol. 38, 564-572. doi: 10.1111/j.0908-8857.2007.04030.x

Isaksson, C., and Andersson, S. (2008). Oxidative stress does not influence carotenoid mobilization and plumage pigmentation. Proc. R. Soc. B Biol. Sci. 275, 309-314. doi: 10.1098/rspb.2007.1474

Isaksson, C., Örnborg, J., Eiríkur, S., and Andersson, S. (2005). Plasma glutathione and carotenoid coloration as potential biomarkers of environmental stress in great tits. Ecohealth 2, 138-146. doi: 10.1007/s10393-005-3869-5

Isaksson, C., Uller, T., and Andersson, S. (2006). Parental effects on carotenoidbased plumage coloration in nestlings great tits, Parus major. Behav. Ecol. Sociobiol. 60, 556-562. doi: 10.1007/s00265-006-0200-6

Isaksson, C., Von Post, M., and Andersson, S. (2007). Sexual, seasonal, and environmental variation in plasma carotenoids in great tits, Parus major. Biol. J. Linnean Soc. 92, 521-527. doi: 10.1111/j.1095-8312.2007.00852.x

Jokimäki, J., Suhonen, J., Jokimäki-Kaisanlahti, M.-L., and Carbó-Ramírez, P. (2016). Effects of urbanization on breeding birds in european towns: impacts of species traits. Urban Ecosyst. 19, 1565-1577. doi: 10.1007/s11252-014-0423-7

Jones, T. M., Rodewald, A. D., and Shustack, D. P. (2010). Variation in plumage coloration of northern cardinals in urbanizing landscapes. Wilson J. Ornithol. 122, 326-333. doi: 10.1676/09-082.1

Kark, S., Iwaniuk, A., Schalimtzek, A., and Banker, E. (2007). Living in the city: can anyone become an 'urban exploiter'? J. Biogeogr. 34, 638-651. doi: $10.1111 / j .1365-2699.2006 .01638 . x$

Lambrechts, M. M., Adriaensen, F., Ardia, D. R., Artemyev, A. V., Atiénzar, F., Bańbura, J., et al. (2010). The design of artificial nestboxes for the study of secondary hole-nesting birds: a review of methodological inconsistencies and potential biases. Acta Ornithol. 45, 1-26. doi: 10.3161/000164510X516047

Lessells, C. M., and Boag, P. T. (1987). Unrepeatable repeatabilities: a common mistake. Auk 104, 116-121. doi: 10.2307/4087240

Lindström, J. (1999). Early development and fitness in birds and mammals. Trends Ecol. Evol. 14, 343-348. doi: 10.1016/S0169-5347(99)01639-0

Mägi, M., Mänd, R., Tamm, H., Sisask, E., Kilgas, P., and Tilgar, V. (2009). Low reproductive success of great tits in the preferred habitat: a role of food availability. Ecoscience 16, 145-157. doi: 10.2980/16-2-3215

McIntyre, N. E. (2000). Ecology of urban arthropods: a review and a call to action. Ann. Entomol. Soc. Am. 93, 825-835. doi: 10.1603/00138746(2000)093[0825:EOUAAR]2.0.CO;2

McIntyre, N. E., Rango, J., Fagan, W. F., and Faeth, S. H. (2001). Ground arthropod community structure in a heterogeneous urban environment. Landsc. Urban Plan. 52, 257-274. doi: 10.1016/S0169-2046(00)00122-5

McKinney, M. L. (2008). Effects of urbanization on species richness: a review of plants and animals. Urban Ecosyst. 11, 161-176. doi: 10.1007/s11252-007-0045-4

Meillère, A., Brischoux, F., Henry, P.-Y., Michaud, B., Garcin, R., and Angelier, F. (2017). Growing in a city: consequences on body size and plumage quality in an urban dweller, the house sparrow (Passer domesticus). Landsc. Urban Plan. 160, 127-138. doi: 10.1016/j.landurbplan.2016.12.014

Meillère, A., Brischoux, F., Parenteau, C., and Angelier, F. (2015a). Influence of urbanization on body size, condition, and physiology in an urban exploiter: a multi-component approach. PLOS ONE 10:e0135685. doi: 10.1371/journal.pone.0135685

Meillère, A., Brischoux, F., Ribout, C., and Angelier, F. (2015b). Traffic noise exposure affects telomere length in nestling house sparrows. Biol. Lett. 11:20150559. doi: 10.1098/rsbl.2015.0559

Metcalfe, N. B., and Monaghan, P. (2001). Compensation for a bad start: grow now, pay later? Trends Ecol. Evol. 16, 254-260. doi: 10.1016/S0169-5347(01) 02124-3
Meyrier, E., Jenni, L., Bötsch, Y., Strebel, S., Erne, B., and Tablado, Z. (2017). Happy to breed in the city? Urban food resources limit reproductive output in western jackdaws. Ecol. Evol. 7, 1363-1374. doi: 10.1002/ece3.2733

Mizutani, Y., Niizuma, Y., and Yoda, K. (2016). How do growth and sibling competition affect telomere dynamics in the first month of life of long-lived seabird? PLoS ONE 11:e0167261. doi: 10.1371/journal.pone.0167261

Møller, A. P. (2008). Flight distance of urban birds, predation, and selection for urban life. Behav. Ecol. Sociobiol. 63, 63-75. doi: 10.1007/s00265-008-0636-y

Møller, A. P. (2009). Successful city dwellers: a comparative study of the ecological characteristics of urban birds in the western palearctic. Oecologia 159, 849-858. doi: 10.1007/s00442-008-1259-8

Møller, A. P., and Ibáñez-Álamo, J. D. (2012). Escape behaviour of birds provides evidence of predation being involved in urbanization. Anim. Behav. 84, 341-348. doi: 10.1016/j.anbehav.2012.04.030

Møller, A. P., Biard, C., Blount, J. D., Houston, D. C., Ninni, P., Saino, N., et al. (2000). Carotenoid-dependant signals: indicators of foraging efficiency, immunocompetence or detoxification ability? Avian Poultry Biol. Rev. 11, 137-159.

Møller, A. P., Díaz, M., Grim, T., Dvorská, A., Flensted-Jensen, E., Ibá-ezÁlamo, J. D., et al. (2015). Effects of urbanization on bird phenology: a continental study of paired urban and rural populations. Clim. Res. 66, 185-199. doi: 10.3354/cr01344

Møller, A. P., Erritzøe, J., and Karadaş, F. (2010). Levels of antioxidants in rural and urban birds and their consequences. Oecologia 163, 35-45. doi: 10.1007/s00442-009-1525-4

Monaghan, P. (2008). Early growth conditions, phenotypic development and environmental change. Philos. Trans. R. Soc. B 363, 1635-1645. doi: 10.1098/rstb.2007.0011

Monaghan, P. (2010). Telomeres and life histories: the long and the short of it. Ann. N. Y. Acad. Sci. 1206, 130-142. doi: 10.1111/j.1749-6632.2010.05705.x

Monaghan, P. (2014). Organismal stress, telomeres and life histories. J. Exp. Biol. 217, 57-66. doi: 10.1242/jeb.090043

Monaghan, P., Metcalfe, N. B., and Torres, R. (2009). Oxidative stress as a mediator of life history trade-offs: mechanisms, measurements and interpretation. Ecol. Lett. 12, 75-92. doi: 10.1111/j.1461-0248.2008.01258.x

Naef-Daenzer, B., and Keller, L. F. (1999). The foraging perfomance of great and blue tits (Parus major and P. Caeruleus) in relation to caterpillar development, and its consequences for nestling growth and fledging weight. J. Anim. Ecol. 68, 708-718. doi: 10.1046/j.1365-2656.1999.00318.x

Naef-Daenzer, B., Widmer, A., and Nuber, M. (2001). Differential post-fledging survival of great and coal tits in relation to their condition and fledging date. J. Anim. Ecol. 70, 730-738. doi: 10.1046/j.0021-8790.2001.00533.x

Nussey, D. H., Baird, D., Barrett, E., Boner, W., Fairlie, J., Gemmell, N., et al. (2014). Measuring telomere length and telomere dynamics in evolutionary biology and ecology. Methods Ecol. Evol. 5, 299-310. doi: 10.1111/2041-210X.12161

Örnborg, J., Andersson, S., Griffith, S. C., and Sheldon, B. C. (2002). Seasonal changes in a ultraviolet structural colour signal in blue tits, parus caeruleus. Biol. J. Linnean Soc. 76, 237-245. doi: 10.1046/j.1095-8312.2002.00061.x

Parolini, M., Romano, A., Khoriauli, L., Nergadze, S. G., Caprioli, M., Rubolini, D., et al. (2015). Early-life telomere dynamics differ between the sexes and predict growth in the barn swallow (Hirundo rustica). PLoS ONE 10:e0142530. doi: 10.1371/journal.pone.0142530

Peters, A., Delhey, K., Johnsen, A., and Kempenaers, B. (2007). The conditiondependent development of carotenoid-based and structural plumage in nestling blue tits: Males and females differ. Am. Nat. 169, S122-S136. doi: $10.1086 / 510139$

Pike, T. W., Blount, J. D., Lindström, J., and Metcalfe, N. B. (2007). Dietary carotenoid availability influences a male's ability to provide parental care. Behav. Ecol. 18, 1100-1105. doi: 10.1093/beheco/arm084

Quesada, J., and Senar, J. C. (2006). Comparing plumage colour measurements obtained directly from live birds and from collected feathers. J. Avian Biol. 37, 609-616. doi: 10.1111/j.0908-8857.2006.03636.x

Riddington, R., and Gosler, A. G. (1995). Differences in reproductive success and parental qualities between habitats in the great tit Parus major. Ibis 137, 371-378. doi: 10.1111/j.1474-919X.1995.tb08035.x

Robb, G. N., McDonald, R. A., Chamberlain, D. E., and Bearhop, S. (2008). Food for thought: supplementary feeding as a driver of ecological change in avian populations. Front. Ecol. Environ. 6, 476-484. doi: 10.1890/060152 
Roux, K. E., and Marra, P. P. (2007). The presence and impact of environmental lead in passerine birds along an urban to rural land use gradient. Arch. Environ. Contam. Toxicol. 53, 261-268. doi: 10.1007/s00244-006-0174-4

Saino, N., Ambrosini, R., Martinelli, R., Ninni, P., and Møller, A. P. (2003a). Gape coloration reliably reflects condition and immunocompetence of barn swallow (Hirundo rustica) nestlings. Behav. Ecol. 14, 16-22. doi: 10.1093/beheco/ 14.1.16

Saino, N., Ferrari, R. P., Romano, M., Martinelli, R., and Møller, A. P. (2003b). Experimental manipulation of egg carotenoids affects immunity of barn swallow nestlings. Proc. R. Soc. B Biol. Sci. 270, 2485-2489. doi: 10.1098/rspb.2003.2534

Salmón, P., Nilsson, J. F., Nord, A., Bensch, S., and Isaksson, C. (2016). Urban environment shortens telomere length in nestling great tits, Parus major. Biol. Lett. 12:20160155. doi: 10.1098/rsbl.2016.0155

Sauvajot, R. M., Buechner, M., Kamradt, D. A., and Schonewald, C. M. (1998). Patterns of human disturbance and response by small mammals and birds in chaparral near urban development. Urban Ecosyst. 2, 279-297. doi: 10.1023/A:1009588723665

Schoech, S. J., Bowman, R., Bridge, E. S., and Boughton, R. K. (2007). Baseline and acute levels of corticosterone in florida scrub-jays (Aphelocoma coerulescens): Effects of food supplementation, suburban habitat, and year. Gen. Comp. Endocrinol. 154, 150-160. doi: 10.1016/j.ygcen.2007.05.027

Senar, J. C., Figuerola, J., and Domènech, J. (2003). Plumage coloration and nutritional condition in the great tit Parus major: the roles of carotenoids and melanins differ. Naturwissenschaften 90, 234-237. doi: 10.1007/s00114-003-0414-7

Seress, G., Bókony, V., Heszberger, J., and Liker, A. (2011). Response to predation risk in urban and rural house sparrows. Ethology 117, 896-907. doi: 10.1111/j.1439-0310.2011.01944.x

Seress, G., Bókony, V., Pipoly, I., Szép, T., Nagy, K., and Liker, A. (2012). Urbanization, nestling growth and reproductive success in a moderately declining house sparrow population. J. Avian Biol. 43, 403-414. doi: 10.1111/j.1600-048X.2012.05527.x

Shanahan, D. F., Strohbach, M. W., Warren, P. S., and Fuller, R. A. (2014). "The challenges of urban living," in Avian Urban Ecology: Behavioural and Physiological Adaptations, eds D. Gil and H. Brumm (Oxford: Oxford University Press), 3-20.

Shawkey, M. D., and Hill, G. E. (2005). Carotenoids need structural colours to shine. Biol. Lett. 1, 121-124. doi: 10.1098/rsbl.2004.0289

Shochat, E., Stefanov, W. L., Whitehouse, M. E. A., and Faeth, S. H. (2004). Urbanization and spider diversity: influences of human modification of habitat structure and productivity. Ecol. Appl. 14, 268-280. doi: 10.1890/02-5341

Shochat, E., Warren, P. S., Faeth, S. H., McIntyre, N. E., and Hope, D. (2006). From patterns to emerging processes in mechanistic urban ecology. Trends Ecol. Evol. 21, 186-191. doi: 10.1016/j.tree.2005.11.019

Sillanpää, S., Salminen, J.-P., Lehikoinen, E., Toivonen, E., and Eeva, T. (2008). Carotenoids in a food chain along a pollution gradient. Sci. Tot. Environ. 406, 247-255. doi: 10.1016/j.scitotenv.2008.07.065

Slabbekoorn, H., and Peet, M. (2003). Ecology: birds sing at a higher pitch in urban noise. Nature 424, 267-267. doi: 10.1038/424267a
Snow, D. W. (1954). Trends in geographical variation in palaerctic members of the genus parus. Evolution 8, 19-28. doi: 10.2307/2405662

Sol, D., Lapiedra, O., and González-Lagos, C. (2013). Behavioural adjustments for a life in the city. Anim. Behav. 85, 1101-1112. doi: 10.1016/j.anbehav.2013.01.023

Spoelstra, K., and Visser, M. E. (2014). "The impact of artificial light on avian ecology," in Avian Urban Ecology: Behavioural and Physiological Adaptations, eds D. Gil and H. Brumm (Oxford: Oxford University Press), 21-28.

Stauffer, J., Panda, B., Eeva, T., Rainio, M., and Ilmonen, P. (2017). Telomere damage and redox status alterations in free-living passerines exposed to metals. Sci. Tot. Environ. 575, 841-848. doi: 10.1016/j.scitotenv.2016.09.131

Stier, A., Massemin, S., Zahn, S., Tissier, M., and Criscuolo, F. (2015). Starting with a handicap: effects of asynchronous hatching on growth rate, oxidative stress and telomere dynamics in free-living great tits. Oecologia 179, 999-1010. doi: 10.1007/s00442-015-3429-9

Stracey, C. M., and Robinson, S. K. (2012). Are urban habitats ecological traps for a native songbird? Season-long productivity, apparent survival, and site fidelity in urban and rural habitats. J. Avian Biol. 43, 50-60. doi: 10.1111/j.1600-048X.2011.05520.x

Thorogood, R., Ewen, J. G., and Kilner, R. M. (2011). Sense and sensitivity: Responsiveness to offspring signals varies with the parents' potential to breed again. Proc. R. Soc. B Biol. Sci. 278, 2638-2645. doi: 10.1098/rspb.2010.2594

Toledo, A., Andersson, M. N., Wang, H.-L., Salmón, P., Watson, H., Burdge, G. C., et al. (2016). Fatty acid profiles of great tit (Parus major) eggs differ between urban and rural habitats, but not between coniferous and deciduous forests. Sci. Nat. 103, 55. doi: 10.1007/s00114-016-1381-0

Tremblay, I., Thomas, D., Blondel, J., Perret, P., and Lambrechts, M. M. (2005). The effect of habitat quality on foraging patterns, provisioning rate and nestling growth in Corsican Blue Tits Parus caeruleus. Ibis 147, 17-24. doi: 10.1111/j.1474-919x.2004.00312.x

Tschirren, B., Fitze, P. S., and Richner, H. (2003). Proximate mechanisms of variation in the carotenoid-based plumage coloration of nestling great tits (Parus major L.). J. Evol. Biol. 16, 91-100. doi: 10.1046/j.1420-9101.2003.00483.x

von Zglinicki, T. (2002). Oxidative stress shortens telomeres. Trends Biochem. Sci. 27, 339-344. doi: 10.1016/S0968-0004(02)02110-2

Zanette, L., Smith, J. N. M., Oort, H. V., and Clinchy, M. (2003). Synergistic effects of food and predators on annual reproductive success in song sparrows. Proc. R. Soc. Lond. Ser. B Biol. Sci. 270, 799-803. doi: 10.1098/rspb.2002.2311

Conflict of Interest Statement: The authors declare that the research was conducted in the absence of any commercial or financial relationships that could be construed as a potential conflict of interest.

Copyright (c) 2017 Biard, Brischoux, Meillère, Michaud, Nivière, Ruault, Vaugoyeau and Angelier. This is an open-access article distributed under the terms of the Creative Commons Attribution License (CC BY). The use, distribution or reproduction in other forums is permitted, provided the original author (s) or licensor are credited and that the original publication in this journal is cited, in accordance with accepted academic practice. No use, distribution or reproduction is permitted which does not comply with these terms. 